\title{
The Government of Sri Lanka launches nanotechnology as a priority research area
}

The Government of Sri Lanka together with the Ministry of Science and Technology launched the Sri Lanka Nanotechnology Initiative in 2007 with the setting up of a Nanotechnology Company (NANCO) with BOI status. A 60 acre property in Homagama has already been ear marked for this project with the Government pledging to allocate over Rs. 5 billion over the next five years. NANCO will become a holding company in the "science park" to be created in Homagama where new nanotechnology inventions will be commercialized by interested private companies.

Coupled to this venture, Sri Lanka Institute of Nanotechnology (SLINTEC), whose goals are more immediate, was set up in 2008 as a private company. SLINTEC is a Rs. 420 million venture with the Government investing 50\% and five joint venture partners namely Hayleys, Mas Holdings, Brandix, Loadstar and Dialog equally investing the rest. The Ministry of Science and Technology is the focal point of the Government's investment which will oversee its responsibilities through the National Science Foundation. Under its mandate, SLINTEC will provide an industrial platform, based on nanotechnology research solutions within three years, to the existing product line up of these companies, thus enhancing their global competiveness.

Nanotechnology is the creation and manipulation of materials 100 nanometers or less with a nanometer amounting to a billionth of a meter; it is ultimately the manipulation of atoms and molecules leading to the fabrication of nano-structured materials. These nano materials possess very different physical, chemical, electrical, or optical properties compared to their bulk state. Thus, nanotechnology provides the tools to do cutting edge research, where it becomes an enabling technology encompassing chemistry, physics, engineering and biology.

There has been an infusion of major funding in developed countries such as the US, Japan and the EU where expectations are high that nanotechnology would become a multitrillion dollar industry by the year 2015. In concert to these efforts, developing nations such as India, China, Brazil, Malaysia, South Africa, Argentina, Chile, Mexico, Philippines, and Thailand too have invested a good percentage of their science and technology budgets to promote nanotechnology. To these developing countries nanotechnology would not only provide an opportunity to leap frog their technological base but also solve their economic, social and environmental problems. No doubt Sri Lanka's entry into nanotechnology research is timely and visionary.

SLINTEC which will begin research in July 2009 will be equipped with sophisticated and costly instrumentation (purchased through NANCO) and a "clean room" suited for nano fabrication. For an individual researcher these start up costs are prohibitive but when you blend research communities together, as achieved at SLINTEC, it would create interdisciplinary synergies that could lead to significant breakthroughs.

Investment into nanotechnology "technopreneurship" through NANCO and SLINTEC, the Government has recognized that scientists can make a big difference in national development by helping to exploit good technologies. However, nanotechnology should be implemented with care and synergy with the environment and a careful life cycle analysis of products. For example, several reports allude to the toxic effects caused by the release of nano particles to the environment. Since benefits would out weight pit falls, it is essential that the scientific community in Sri Lanka begin an "upstream" dialogue with the public and solve the problems that nanotechnology may lead to while carrying out research. In this regard, it is important to note that SLINTEC is committed to sustainable nanotechnology where a sustainability screen would be applied to all the research they undertake. 
Nanotechnology is still in the 'infancy' stage where the big breakthroughs may appear in any nation at any time and Sri Lanka's presence in this global research effort augurs well for its future. Finally, in these exiting times of nanotechnology research in Sri Lanka, scientists have a golden opportunity to make the nation proud by elevating 'Made in Sri Lanka' to a quality label in nanotechnology products.

\section{Veranja Karunaratne}

